\title{
Signal detection to identify serious adverse events (neuropsychiatric events) in travelers taking mefloquine for chemoprophylaxis of malaria
}

This article was published in the following Dove Press journal:

Drug, Healthcare and Patient Safety

2 August 2012

Number of times this article has been viewed

\author{
Cho Naing ${ }^{1,3}$ \\ Kyan Aung' \\ Syed Imran Ahmed ${ }^{2}$ \\ Joon Wah Mak ${ }^{3}$
}

'School of Medical Sciences, ${ }^{2}$ School of Pharmacy and Health Sciences,

${ }^{3}$ School of Postgraduate Studies and Research, International Medical University, Kuala Lumpur, Malaysia

Correspondence: Cho Naing International Medical University, Kuala Lumpur 57000, Malaysia

Tel +60386567228

Fax +60386567229

Email cho_naing@imu.edu.my
Background: For all medications, there is a trade-off between benefits and potential for harm. It is important for patient safety to detect drug-event combinations and analyze by appropriate statistical methods. Mefloquine is used as chemoprophylaxis for travelers going to regions with known chloroquine-resistant Plasmodium falciparum malaria. As such, there is a concern about serious adverse events associated with mefloquine chemoprophylaxis. The objective of the present study was to assess whether any signal would be detected for the serious adverse events of mefloquine, based on data in clinicoepidemiological studies.

Materials and methods: We extracted data on adverse events related to mefloquine chemoprophylaxis from the two published datasets. Disproportionality reporting of adverse events such as neuropsychiatric events and other adverse events was presented in the $2 \times 2$ contingency table. Reporting odds ratio and corresponding 95\% confidence interval [CI] data-mining algorithm was applied for the signal detection. The safety signals are considered significant when the ROR estimates and the lower limits of the corresponding $95 \% \mathrm{CI}$ are $\geq 2$.

Results: Two datasets addressing adverse events of mefloquine chemoprophylaxis (one from a published article and one from a Cochrane systematic review) were included for analyses. Reporting odds ratio $1.58,95 \% \mathrm{CI}$ : $1.49-1.68$ based on published data in the selected article, and $1.195,95 \%$ CI: $0.94-1.44$ based on data in the selected Cochrane review. Overall, in both datasets, the reporting odds ratio values of lower $95 \%$ CI were less than 2 .

Conclusion: Based on available data, findings suggested that signals for serious adverse events pertinent to neuropsychiatric event were not detected for mefloquine. Further studies are needed to substantiate this.

Keywords: mefloquine, signal detection, reporting odds ratio, neuropsychiatric events

\section{Introduction}

With increasing international travel across countries, including those in malariaendemic regions, and the continued spread of resistance to antimalarial drugs, travelers are at risk for contracting malaria. ${ }^{1}$ Travelers who are naturally vulnerable because of lowered immunity, such as young children, people with chronic diseases, elderly people, and pregnant women, now travel more frequently; consequently, imported malaria is observed more often in these subgroups., ${ }^{2,3}$ Although imported malaria is preventable, many travelers fail to use or comply with appropriate chemoprophylaxis due to concerns regarding side effects associated with antimalarial chemoprophylaxis. ${ }^{4}$

There is a consensus that the ideal chemoprophylactic medication should be highly effective, cause few or no adverse events (AEs), be appropriate for all travelers, including pregnant women, nursing mothers, small children, long-term travelers, should 
be cheap and easy to use and should be registered globally for this indication. ${ }^{5} \mathrm{An} \mathrm{AE}$ is classified as "any undesirable medical occurrence that develops after the administration of a drug, regardless of the suspected relationship between the drug product and the event". In order to classify an event as an adverse drug reaction (ADR), a causal relationship must be established. ${ }^{6,7}$ In the present analysis, a serious adverse event (SAE) was defined as any adverse experience that resulted in death, a life-threatening experience, participant hospitalization, or persistent or significant disability or incapacity. We also examined specific medical or surgical intervention to prevent serious outcomes. ${ }^{8,9}$

Currently, three main antimalarial drugs, atovaquoneproguanil, doxycycline, and mefloquine (MFQ), are used as chemoprophylaxis for those traveling to regions with known chloroquine-resistant Plasmodium falciparum malaria. ${ }^{4}$

MFQ has been available for malaria chemoprophylaxis since 1985 in Europe and since 1990 in the USA. ${ }^{5}$ Due to the drug's characteristics of schizontocidal action against the blood stages of all human malaria species including P. knowlesi,${ }^{10}$ its affordability, and because it is administered once weekly resulting in good adherence, MFQ is an effective malaria chemoprophylaxis for travelers going to high risk chloroquine-resistant $P$. falciparum areas ${ }^{5}$ in the Thai border regions known to have multidrug resistance. ${ }^{5}$ To date, the drug is used clinically as a 50:50 racemic mixture of the erythro isomers and all clinical studies involving this drug have used this mixture. ${ }^{5}$

The Cochrane systematic review incorporated eight randomized controlled trials (RCTs) with 4240 participants to assess currently used antimalarial drugs including MFQ for chemoprophylaxis of malaria in travelers. In the review, no SAEs were reported. ${ }^{4}$ Overall, pregnant women who took MFQ at various doses for both prevention and treatment of malaria did not have an increased risk of teratogenic effects (birth defects) or adverse pregnancy outcomes compared to the background rate in the general population. ${ }^{11}$ In contrast, the risk of AEs, particularly neuropsychiatric AEs, related to the prophylactic use of MFQ, has also been reported, ${ }^{1}$ which adversely affects compliance ${ }^{12}$ or may result in switching to less-effective alternatives. Studies have also identified severe psychiatric side effects related to the use of MFQ in preventing malaria. ${ }^{13,14}$ A study involving US military personnel deployed to Afghanistan reported that approximately one in seven individuals with neuropsychiatric contraindications received a prescription for MFQ prior to combat deployment. ${ }^{15}$ Thus, from the aspect of patient safety, potential harm to the prospective users must be identified.
Pharmacovigilance is defined as "the science and activities relating to the detection, assessment, understanding and prevention of adverse effects or any other possible drug related problem" ${ }^{6,9}$ Two broad approaches for pharmacovigilance are used in developed countries, including passive spontaneous reporting systems and systems utilizing pharmacoepidemiological methods. ${ }^{7,16}$ The latter approach can be applied to data from clinical trials if the sample size is adequate to assess risks in multiple arm treatments and if the collection of safety data is standardized to ensure high quality. ${ }^{?}$

\section{Materials and methods Study objective}

The aim of the present study was to identify signals of SAEs resulting from the use of MFQ based on data from clinicoepidemiological studies.

\section{Data source}

In order to illustrate the signal detection for identifying SAEs in travelers taking MFQ for chemoprophylaxis, data from two sources, an individual study and the pooled data of RCTs, were extracted. We collected AE-related data from published studies and from a Cochrane systematic review. The data were from the empirical studies rather than that submitted by physicians, pharmacists, other health care professionals, manufacturers, or consumers. However, these data could be regarded as being spontaneously reported AEs by researchers because they (i) highlight the disproportionality, (ii) allow for estimation of relative risks, (iii) can give rise to less bias than case reports, and (iv) are available for calculations of disproportionality based upon presentation in a $2 \times 2$ contingency table. In order to reflect the spontaneous reporting manner, we collected data according to the year the study was conducted. If duplicate reports for the same patient but from different sources were noted, only the latest updated data were included.

Clinical judgment was applied to identify neuropsychiatric events as defined by the medical dictionary for regulatory activities preferred terms (Table 1). ${ }^{17}$

\section{Data analyses}

The association between antimalarial drugs, including MFQ, and neuropsychiatric events was analyzed using the reporting odds ratio (ROR) and corresponding 95\% confidence interval (CI) data-mining algorithm. ROR values for MFQ denote the ratio of the observed to the expected number of reported neuropsychiatric events compared with other antimalarial drugs in the data set during the analysis period. Values less 
Table I Selected MedDRA preferred terms that reflect neuropsychiatric events

\begin{tabular}{ll}
\hline Category & Preferred terms \\
\hline Delirium & Delirium \\
Delusions/perceptual & Delirium febrile \\
disturbance & Delusion \\
& Delusional perception \\
& Hallucination \\
& Hallucination, auditory \\
& Hallucination, visual \\
& Hallucinations, mixed \\
& Illusion \\
& Paranoia \\
Suicidal events & Completed suicide \\
& Self-injurious behavior \\
& Self-injurious ideation \\
& Suicidal ideation \\
Convulsion & Suicide attempt \\
& Grand mal convulsion \\
& Clonic convulsion \\
Abnormal behavior & Convulsion \\
Epilepsy \\
of consciousness & Febrile convulsion \\
& Partial seizures \\
Status epilepticus & Tonic convulsion \\
& Altered state of consciousness \\
& Consciousness fluctuating \\
& Depressed level of consciousness \\
& Abnormal behavior \\
\hline & \\
&
\end{tabular}

Note: Each term category has multiple verbatim terms identified. Abbreviation: MedDRA, Medical Dictionary for Regulatory Activities.

than 1 indicate no exposure-event association, while values greater than 1 indicate exposure-event safety signals. From the regulatory science perspective, safety signals are considered significant when the ROR estimates and the lower limits of the corresponding $95 \% \mathrm{CI}$ are $\geq 2 .{ }^{18}$

Table 2 shows the data-mining algorithm to calculate point estimates of ROR and the corresponding $95 \%$ CI for MFQ and comparators in the study. Data entry and analyses were performed using a Microsoft Excel (Microsoft, Redmond, WA) spreadsheet.

Table 2 The $2 \times 2$ contingency table used for calculating reporting odds ratios and $95 \% \mathrm{Cl}$ data-mining algorithm

\begin{tabular}{|c|c|c|c|}
\hline Exposure & $\begin{array}{l}\text { Neuropsychiatric } \\
\text { events }\end{array}$ & $\begin{array}{l}\text { Other } \\
\text { AEs }\end{array}$ & Total \\
\hline Mefloquine & $A$ & B & $A+B$ \\
\hline Other antimalarial drugs & $\mathrm{C}$ & $\mathrm{D}$ & $C+D$ \\
\hline Total & $A+C$ & $B+D$ & $\mathrm{~N}$ \\
\hline \multicolumn{4}{|l|}{ ROR: $\underline{A / B}$} \\
\hline$C / D$ & & & \\
\hline $95 \% \mathrm{Cl}: \mathrm{e}^{\ln (\mathrm{ROR}) \pm 1.96 \sqrt{\mathrm{N} / \mathrm{A}+}}$ & & & \\
\hline
\end{tabular}

Abbreviations: $A E$, adverse event; ROR, reporting odds ratio.

\section{Results}

Two data sets were identified for this analysis. The Barrett data $^{19}$ compared MFQ and a combination drug of chloroquine and proguanil. The Cochrane database ${ }^{4}$ assessed multiple comparisons including MFQ, atovaquone-proguanil, and doxycycline. Regarding the source of data collection, the former was from a retrospective survey ( $\mathrm{n}=1214$ adults), while the latter was from eight RCTs ( $\mathrm{n}=4240$ adults). The distribution of SAEs in travelers taking MFQ as a chemoprophylaxis and the respective data sources ${ }^{19-22}$ are shown in Tables 3 and 4.

Based on our estimates from of the two database sources, the estimated RORs and their corresponding $95 \%$ CI datamining algorithm for MFQ are presented in Tables 5 and 6. In both data sources, ROR values with low $95 \%$ CI values were less than 2. This indicates that signals for SAE pertinent to neuropsychiatric events were not detected.

\section{Discussion}

For all medications, there is a trade-off between the benefits and the potential for harm; these factors should be analyzed and communicated effectively as part of an effective approach towards pharmacovigilance. ${ }^{6}$ Anecdotal reports can identify the occurrence of an $\mathrm{AE}$ that may be coincidental ${ }^{23}$ rather than actual harm. It is important for patient safety to detect drug-event combinations and analyze these events using appropriate statistical methods. ${ }^{24,25}$ The present study provides information regarding the safety level of MFQ in adult travelers in the context of pharmacovigilance. As the ROR estimates and the lower limits of the corresponding 95\% CI were $<2$ in both database sources in the present analysis, a safety signal was not detected.

Upon comparison of MFQ with the single comparator quinine or a combination drug (ie, chloroquine plus proguanil) in the present analysis, "signal dilution" ${ }^{26}$ was not observed. As data collection is expensive, data-mining processes are often performed using existing databases for the purpose of pharmacovigilance. ${ }^{6,27}$ Regarding the methodology of the

Table 3 Distribution of adverse events in travelers taking mefloquine chemoprophylaxis

\begin{tabular}{llll}
\hline Adverse events & \multicolumn{2}{l}{ Reported serious AE } & Remarks \\
\cline { 2 - 3 } & $\begin{array}{l}\text { MFQ } \\
\text { alone }\end{array}$ & $\begin{array}{l}\text { Chloroquine } \\
\text { plus proguanil }\end{array}$ \\
\hline Nervous system AE & 31 & 12 & Serious AE \\
Gl-related AE & 26 & 16 & Nonserious AE \\
Other nonserious AE & 20 & 19 & Nonserious AE \\
\hline
\end{tabular}

Notes: Derived from data in Barretts et al. ${ }^{19}$

Abbreviations: $\mathrm{AE}$, adverse event; $\mathrm{Gl}$, gastrointestinal symptoms; $\mathrm{MFQ}$, mefloquine. 
Table 4 Distribution of serious adverse events in preventing malaria in travelers

\begin{tabular}{lllll}
\hline Study reference no & Year of publication & MFQ & Comparator & Adverse events \\
\hline 20 & 2003 & 36 & $34^{\mathrm{a}}$ & Dermatological reaction \\
1 & $200 \mathrm{I}$ & 15 & $12^{\mathrm{a}}$ & Do \\
20 & 2003 & 89 & $88^{\mathrm{a}}$ & Gastrointestinal symptoms \\
1 & $200 \mathrm{I}$ & 94 & $77^{\mathrm{a}}$ & Gastrointestinal symptoms \\
20 & 2003 & 118 & $109^{\mathrm{a}}$ & Neuropsychiatric \\
1 & 2001 & 139 & $69^{\mathrm{a}}$ & Do \\
1 & $200 \mathrm{I}$ & 10 & $4^{\mathrm{a}}$ & Serious adverse events \\
20 & 2003 & 0 & $0^{\mathrm{a}}$ & Do \\
21 & 1997 & 22 & $22^{\mathrm{b}}$ & Dermatological reaction \\
20 & 2003 & 45 & $42^{\mathrm{b}}$ & Do \\
21 & 1997 & 29 & $16^{\mathrm{b}}$ & Gastrointestinal symptoms \\
20 & 2003 & 89 & $81^{\mathrm{b}}$ & Do \\
22 & 1990 & 64 & $58^{\mathrm{b}}$ & Do \\
20 & 1997 & 38 & $22^{\mathrm{b}}$ & Neuropsychiatric \\
1 & 2003 & 118 & $115^{\mathrm{b}}$ & Do \\
22 & 1990 & 10 & $6^{\mathrm{b}}$ & Do \\
\hline
\end{tabular}

Notes: ${ }^{a}$ Comparator is atovaquone-proguanil; ${ }^{b}$ comparator is doxycycline. Derived from primary studies included in Jacquerioz and Croft. ${ }^{4}$ Abbreviation: MFQ, mefloquine.

data-mining process, measures of disproportionality are the only techniques which have been used to identify AEs. ${ }^{27}$ The current analysis followed this approach as well.

Spontaneous reporting to the World Health Organization or to the Food and Drug Administration may provide data on a broad spectrum of patients. Moreover, ADRs that occur after prolonged exposure or ADRs that are extremely rare can be detected through spontaneous reports. However, the absence of a control group and the lack of a denominator indicate that the attributable rate of the ADR cannot be calculated. ${ }^{28}$ Case reports are the main source of information used to withdraw a drug from the market for safety reasons. ${ }^{29}$ In assessing the culprit drug, it is difficult to determine whether the report is a genuine alert or a false alarm..$^{30}$ The aim of the present study was not to examine the reporting system, but to highlight the usefulness of other published data sources for signal detection.

The risk of malaria during travel is determined by immunological characteristics of the individual traveler (the person),

Table 5 Reporting odds ratio and $95 \% \mathrm{Cl}$ data-mining algorithm for mefloquine alone

\begin{tabular}{llll}
\hline Exposure & $\begin{array}{l}\text { Neuropsychiatric } \\
\text { events }\end{array}$ & $\begin{array}{l}\text { Other } \\
\text { AEs }\end{array}$ & Total \\
\hline Mefloquine & 31 & 46 & 77 \\
Other antimalarial drugs & 12 & 35 & 47 \\
Total & 43 & 81 & 124 \\
ROR: A/B & 1.58 & & \\
C/D & & & \\
$95 \% \mathrm{Cl}$ & $1.49-1.68$ & & \\
\hline
\end{tabular}

Note: Data derived from Table 3.

Abbreviations: $\mathrm{AE}$, adverse event; $\mathrm{Cl}$, confidence interval; $\mathrm{ROR}$, reporting odds ratio. the travel destination (the place), and the use of preventive anti-mosquito measures and adequate chemoprophylaxis (prevention without and with drugs). ${ }^{4}$ In the present study, based on two different data sources, signals for neuropsychiatric event were not detected. Importantly, if a signal is not detected, it is impossible to determine whether no AEs (neuropsychiatric event in our case) exist or whether the data are insufficient. ${ }^{27}$ Further studies are needed to substantiate this hypothesis. Nevertheless, as our data pertinent to the second database were rooted in RCTs, our estimation of signal detection is less likely to exhibit bias. Additionally, approximately one in seven individuals with neuropsychiatric contraindications received a prescription for MFQ prior to combat deployment. ${ }^{15}$ Travelers and the deployment groups cannot necessarily be equated. Deployment may result in psychiatric casualties that are either the result of inadequate coping with deployment stressors or acute stress reactions caused by battle trauma or combat stress reactions. ${ }^{31}$ Stress-inducing factors compounded to the effect of MFQ may be a likely cause of neuropsychiatric events in this population. In pharmacovigilance and in medicine in gen-

Table 6 Reporting odds ratio and $95 \% \mathrm{Cl}$ data-mining algorithm for mefloquine in travelers

\begin{tabular}{lll}
\hline & Neuropsychiatric & Others AE \\
\hline Mefloquine & 257 & 286 \\
Other antimalarial & 200 & 266 \\
ROR: A/C & 1.195 & \\
B/D & & \\
$95 \% \mathrm{Cl}$ & $0.94-1.44$ & \\
\hline
\end{tabular}

Notes: Data derived from Table 4; afocusing on gastrointestinal symptoms. Abbreviation: $\mathrm{AE}$, adverse event; $\mathrm{Cl}$, confidence interval; $\mathrm{ROR}$, reporting odds ratio. 
eral, it is important to be cognizant of interactions, not only between drugs but also between drugs and diseases as well as environmental factors. As such, nondrug interactions may act as confounders when they are actually co-precipitating factors ${ }^{25}$ in this special population.

We were unable to identify a signal for detection based on two datasets in which study time and participants were not the same. Thus, whether drug-events were related to MFQrelated neuropsychiatric effects did not vary significantly over time. Second, there was a relatively higher frequency of neuropsychiatric AEs related to MFQ than to comparator drugs although they were not related to SAEs. This highlights the need for clinical surveillance of MFQ chemoprophylaxis with stratification by gender or age group.

Notably, no individual approach to detect signals (ROR in our case) is adequate and the concurrent use of other methods is therefore essential. ${ }^{32}$ Further incorporation of pharmacovigilance principles into clinical practice and academic medicine is necessary. ${ }^{6}$ As such, published studies have postulated that neurologic syndromes in patients induced by MFQ were likely due to a central anticholinergic syndrome. ${ }^{32}$ Although multiple factors may have contributed to cognitive impairment, the temporal relationship between symptom onset and MFQ use suggests a high likelihood that MFQ was the causal factor; ${ }^{33}$ hence, further studies are warranted. There may be important differences between the pharmacokinetic properties of MFQ in pregnancy and nonpregnant adults. ${ }^{34}$ Moreover, we recommend future studies assessing SAE of MFQ for preventing malaria in pregnant women.

\section{Acknowledgments}

We are grateful to the participants and the researchers of the primary studies used for the present analysis. We wish to thank the International Medical University (IMU) Malaysia for allowing us to perform this study. We are grateful to the reviewers for their comments and helpful inputs to improve this manuscript.

\section{Disclosure}

The authors report no conflicts of interest in this work.

\section{References}

1. Overbosch D, Schilthuis H, Bienzle RH, et al. Atovaquone-proguanil versus mefloquine for malaria prophylaxis in nonimmune travelers: results from a randomized, double-blind study. Clin Infect Dis. 2001;33(7):1015-1021.

2. Loutan L. Malaria: still a threat to travellers. Int J Antimicrob Agents. 2003;21(2):158-163.

3. Leder K, Black J, O'Brien D, et al. Malaria in travelers: a review of the GeoSentinel surveillance network. Clin Infect Dis. 2004;15:39(8): 1104-1112.
4. Jacquerioz FA, Croft AM. Drugs for preventing malaria in travellers. Cochrane Database Syst Rev. 2009;4:CD006491.

5. Schlagenhauf P, Adamcova M, Regep L, Schaerer MT, Rhein HG. The position of mefloquine as a 21 st century malaria chemoprophylaxis. Malar J. 2010;9:357.

6. World Health Organization. The Importance of Pharmacovigilance: Safety monitoring of medicinal products. Switzerland, Geneva: WHO; 2002.

7. Talisuna AO, Staedke SG, D'Alessandro U. Pharmacovigilance of antimalarial treatment in Africa: is it possible? Malar J. 2006;5:50.

8. ICTDR (International Centre for Tropical Diseases). Investigator manual. Monitoring and reporting adverse events. 2005 Available from: http://www.icssc.org/Documents/Resources/ ICTDR_AE_Manual_February_6_2003_final.pdf. Accessed May 12, 2012.

9. WHO. A Practical Handbook on the Pharmacovigilance of Medicines used in the Treatment of Tuberculosis: Enhancing the safety of the TB patient. Geneva, Switzerland: WHO; 2002.

10. Singh K, Shanks GD, Wilde H. Seizures after mefloquine. Ann Intern Med. 1991;114(11):994.

11. CDC (Centers for Disease Control and Prevention). Pregnant travellers. 2012. Available from: http://wwwnc.cdc.gov/travel/yellowbook/2012/ chapter-8-advising-travelers-with-specific-needs/pregnant-travelers. htm. Accessed May 3, 2012.

12. Hoebe C, de Munter J, Thijs C. Adverse effects and compliance with mefloquine or proguanil antimalarial chemoprophylaxis. Eur J Clin Pharmacol. 1997;52(4):269-275.

13. Hennequin C, Bouree P, Bazin N, Bisaro F, Feline A. Severe psychiatric side effects observed during prophylaxis and treatment with mefloquine. Arch Int Med. 1994;154:2360-2362.

14. Wells TS, Smith TC, Smith B, et al. Mefloquine use and hospitalizations among US service members, 2002-2004. Am J Trop Med Hyg. 2006;74(5):744-749.

15. Nevin RL. Mefloquine prescriptions in the presence of contraindications: prevalence among US military personnel deployed to Afghanistan, 2007. Pharmacoepidem Drug Safe. 2010;19:206-210.

16. Kuemmerle A, Dodoo AN, Olsson S, Van Erps J, Burri C, Lalvani PS. Assessment of global reporting of adverse drug reactions for antimalarials, including artemisinin-based combination therapy, to the WHO Programme for International Drug Monitoring. Malar J. 2011;10:57.

17. WHO. Introductory Guide MedDRA Version 14.0. 2011. MSSO-DI6003-14.0.0. Available from: http://www.who.int/medical_devices/innovation/MedDRAintroguide_version14_0_March2011.pdf. Accessed May 3, 2012.

18. Bate A, Evans SJW. Quantitative signal detection using spontaneous ADR reporting. Pharmacoepidem. Drug Safe. 2009;18:427-436.

19. Barrett PJ, Emmins PD, Clarke PD, Bradley DJ. Comparison of adverse events associated with use of mefloquine and combination of chloroquine and proguanil as antimalarial prophylaxis: postal and telephone survey of travellers. BMJ. 1996;313(7056):525-528.

20. Schalgenhauf P, Tschopp A, Johnson F, et al. Tolerability of malaria chemoprophylaxis in non-immune travellers to sub-Saharan Africa: multicentre, randomised, double blind, four arm study. BMJ. 2003;327(7423):1078.

21. Ohrt C, Richie TL, Widjaja H, et al. Mefloquine compared with doxycycline for the prophylaxis of malaria in Indonesian soldiers. Ann Intern Med. 1997;126(12):963-972.

22. Arthur JD, Echeverria P, Shanks GD, Karwacki J, Ladaporn B, Brown JE. A comparative study of gastrointestinal infections in United States soldiers receiving doxycycline or mefloquine for malaria prophylaxis. Am J Trop Med Hyg. 1990;43(6):608-613.

23. Walsh $L$. Incidental events in spontaneous reports-a proposal for filtering noise. Br J Clin Pharmacol. 2005;61(1):118-119.

24. Levine JG, Tonning JM, Szarfman A. Reply: The evaluation of data mining methods for the simultaneous and systematic detection of safety signals in large databases: lessons to be learned. Br J Clin Pharmacol. 2005;61(1):105-113. 
25. Edwards R. An agenda for UK clinical pharmacology pharmacovigilance. Br J Clin Pharmacol. 2012;73(6):979-982.

26. Ali AK, Hartzema AG. Assessing the association between omalizumab and arteriothrombotic events through spontaneous adverse event reporting. J Asthma Allergy. 2012;5(1):1-9.

27. Wilson AM, Thabane L, Holbrook A. Application of data mining techniques in pharmacovigilance. Br J Clin Pharmacol. 2004;57(2): 127-134.

28. Loke YK, Derry S, Aronson JK. A comparison of three different sources of data in assessing the frequencies of adverse reactions to amiodarone. Br J Clin Pharmacol. 2004;57:616-621.

29. Arnaiz JA, Carné X, Riba N, Codina C, Ribas J, Trilla A. The use of evidence in pharmacovigilance. Case reports as the reference source for drug withdrawals. Eur J Clin Pharmacol. 2001;57(1):89-91.

30. Higgins JPT, Green S, editors. Cochrane Handbook for Systematic Reviews of Interventions Version 5.1.0 [updated Mar 2011]. The Cochrane Collaboration, 2011. Available from http://www.cochranehandbook.org. Accessed May 12, 2012.
31. Gaylord KM. The psychosocial effects of combat: the frequently unseen injury. Crit Care Nurs Clin North Am. 2006;18(3):349-357.

32. van Puijenbroek EP, van Grootheest K, Diemont WL, Leufkens HG, Egberts AC. Determinants of signal selection in a spontaneous reporting system for adverse drug reactions. Br J Clin Pharmacol. 2001;52(5):579586.

33. Javorsky DJ, Tremont G, Keitner GI, Parmentier AH. Cognitive and neuropsychiatric side effects of mefloquine. $J$ Neuropsychiatry Clin Neurosci. 2001;13:302-302.

34. Nosten F, ter Kuile F, Maelankiri L, et al. Mefloquine prophylaxis prevents malaria during pregnancy: a double blind, placebo controlled study. J Infect Dis. 1994;169:595-603.

\section{Publish your work in this journal}

Drug, Healthcare and Patient Safety is an international, peer-reviewed open-access journal exploring patient safety issues in the healthcare continuum from diagnostic and screening interventions through to treatment, drug therapy and surgery. The journal is characterized by the rapid reporting of reviews, original research, clinical, epidemiological and post-marketing surveillance studies, risk management, health literacy and educational programs across all areas of healthcare delivery. The manuscript management system is completely online and includes a very quick and fair peer-review system. Visit http://www.dovepress.com/ testimonials.php to read real quotes from published authors.

Submit your manuscript here: http://www.dovepress.com/drug-healthcare-and-patient-safety-journal 